\title{
A Survey on the Satisfaction of Diversified Learning Space in Colleges and Universities
}

\author{
Hongbo Shi*, Bohan Gao, Zhuomei Zhou \\ School of Economics and Management, Harbin Institute of Technology, Weihai, China \\ *Corresponding author. Email: shihongbo@hit.edu.cn
}

\begin{abstract}
In recent years, with the continuous development of science, technology, economy and society, the learning space on campus tends to be diversified in form and function. The unexpected COVID-19 epidemic in 2020 objectively promotes the rapid development of e-learning space. However, the research on learning space is not thorough enough currently. In this paper, based on the satisfaction survey of college students' learning space use, we try to find the shortcomings of college learning space, and put forward targeted countermeasures and suggestions.
\end{abstract}

Keywords: College students, Learning space, Satisfaction.

\section{INTRODUCTION}

The influence of environment on a person is multifaceted, and the shaping of our character and thinking is inseparable from the environment. In biology, traits are composed of genes and external environment. From this point of view, we can see that the influence of environment on a person is multifaceted and multifaceted. When we leave middle school and go to college, we are in a diversified learning space. The close relationship between learning environment and students' learning needs no further argument, but it is worth mentioning that many empirical studies at home and abroad show that learning environment support has a significant positive effect on the overall development of college students' ability. Therefore, understanding the complexity of college students' learning environment and providing relevant support is undoubtedly an important link to improve students' learning experience and learning effectiveness.

Based on the impact of diversified learning space on students and the purpose of improving the construction of diversified learning space in colleges and universities, we hope to investigate students' satisfaction with the use of diversified learning space, summarize the deficiencies in the service of learning space in colleges and universities in China, and put forward countermeasures and suggestions, so as to make the learning space in colleges and universities better respond to the "Double First-class" construction and better serve the majority of students' learning.

\subsection{Current Situation of Diversified Learning Space in Colleges and Universities}

From the physical space construction division is more detailed, showing the characteristics of diversification. Including classrooms, study rooms, libraries and other formal learning space, as well as dormitories, cafes and other informal learning space. In addition, it should be emphasized that the popularity of the network has made online teaching and online learning an important extension of learning space.

The COVID-19 started at the end of the year 2019, which has made the network teaching widely practiced all over the world. The immediacy of "Internet + education" has broken the time and space limit of college education, and changed the way and form of learning [1]. As a special and potential part of the diversified learning space, network can attach importance to the updating of knowledge and the adaptive classification of content, equip courses according to different learning needs in the constantly updated subject knowledge system, and solve the problem of learners' adaptability. In addition, the development of Internet provides a possible tool and environment for the realization of interactive teaching.

\subsection{Research Significance}

Colleges and universities shoulder the responsibility of cultivating talents for the society. Learning space is 
the main place for learning, and the environment of learning space directly affects the physical and mental development of learners. With the coming of information age and the construction of learning society, great changes are taking place in learning space. The change of learning style will inevitably lead to the change of learning space. The design of learning space suitable for future learning style will help to promote the development of education and improve learning effectiveness. Therefore, in the process of continuous reform and innovation in colleges and universities, we can always pay attention to the students' demand for diversified learning space and improve the utilization rate of all kinds of learning space, so that the school's learning space can be reasonably allocated and utilized. In addition, carrying out the satisfaction survey of diversified learning space also has a positive significance for the construction of scholarly culture, the construction of learning atmosphere, and the promotion of students' autonomous learning.

\subsection{Research Process Design}

Considering the large number of students in colleges and universities, the main research object is selected as $\mathrm{H}$ University.

In the initial stage, through consulting literature, the diversified learning space in colleges and universities is classified, and a clear definition is given. And then, the relevant data of different types of learning space are consulted to understand the characteristics and current situation of different types of learning space. In the middle of the survey, it was carried out mainly through the form of online questionnaire On the Use of Learning Space of $H$ University Students Satisfaction Survey. After that, the collected data are visualized to form intuitive results.

After the completion of data processing, combined with the literature, the results of data processing are sorted and analyzed, and the corresponding suggestions are given, so as to provide reference for improving the learning space of colleges and universities.

\section{ON LEARNING SPACE}

\subsection{Classification of Learning Space}

Based on constructivist learning theory, learning is a social process in which individuals actively participate in construction in a specific situation [2]. And learning space is the existence of a carrier in this social process. At the same time, the forms of learning space are various.

According to the basic attributes of learning space, it can be divided into formal learning space and informal learning space. It is worth mentioning that due to the impact of this sudden epidemic, many colleges and universities have carried out online teaching mode, and the utilization of online learning space (that is, network learning space) has made a big step forward as a whole.

\subsection{Diversified Learning Space}

\subsubsection{Formal Learning Space}

Formal learning space is actually our traditional learning space, that is, classroom, study room, library and other learning places that most people will quickly associate with. This kind of learning space often has the characteristics of standardization, simplification, static, closed, and being used by the vast majority of students. It usually gathers a lot of students, has a strong learning atmosphere, and creates a "learner centered" form. Among them, library and classroom are the most important formal learning space.

The library has always been the holy land for college students to study, generally including the library (or literature database), reader service area, literature processing and management area, public activity area and auxiliary space. In addition, in addition to all kinds of special learning areas, each floor of the library also has music corner, science and technology corner and other leisure areas, so that students can relax after reading.

The classroom is a conventional place for teachers to teach and students to join. Naturally, it is also an important part of the formal learning space. There are fixed tables and chairs; teaching equipment such as blackboard, platform, projector, desk, etc. In spare time, the classroom is often used as a study room. In the evening or holidays, the empty classrooms will be quickly occupied by students and become a place for autonomous learning.

\subsubsection{Informal Learning Space}

With the change of people's view of knowledge, education and learning, more and more college students no longer focus on the traditional learning space such as classroom and library, but start to explore other space in order to complete their study. Most of the informal learning spaces are opened up from the traditional learning space, which is embodied in the unstructured space under students' self-guidance. Next, detailed introduction and analysis are given.

\subsubsection{Dormitory}

Dormitory is a comprehensive place for college students to study and live, rest and entertainment and interpersonal communication. At the same time, there are many problems in dormitory learning, such as crowded space, poor lighting, and weak learning atmosphere and so on. Therefore, each floor of $\mathrm{H}$ 
University dormitory building is equipped with a selfstudy room of about 40 square meters, with perfect desk and chair equipment, which can be used by students for a long time.

\subsubsection{Canteen}

The dining room is spacious, with air conditioning in winter and summer, and suitable temperature. Besides the meal time, there will be no too much noise in the canteen, and the students will be free from restrictions. Therefore, in non-meal time, some students will choose to carry out group activities and hold community meetings here.

\subsubsection{Cafe}

The informal learning space opened up by the school commercial venues is mainly for profit-making consumption space, and the typical one is the coffee shop located in the activity center of college students. The environment is elegant and the atmosphere is quiet. It is equipped with front desk service area, tables and chairs with a sense of design, drinks and large space. It is divided into two floors, and several private rooms with good sound insulation. Many students will choose to come here for autonomous learning or group discussion in their spare time, and tend to use more private space.

\subsubsection{Online Learning Space}

E-learning space refers to the virtual space supporting online teaching activities. It is the "middle space" of learning management system and open personal learning environment. It not only includes the e-learning space with the core characteristics of multimedia resources network publishing and sharing, but also includes the e-learning space with the core characteristics of interaction and knowledge generation [3]. In the teaching environment, teaching mode, content presentation, learning evaluation and other aspects, it breaks through multiple limitations and realizes the innovation of traditional classroom learning methods. The fundamental difference between online education and traditional education is openness and sharing. It has a large number of free and open courses and resources, students can choose to learn independently, and has a series of characteristics such as timeliness, transmission and sharing, which truly realizes the resource sharing. Through various platform of software, teachers can share the screen to present PPT or audio-visual materials in the way of a "host" to carry out teaching work. Students listen to classes and take notes at home through various terminals, and teachers and students complete the teaching process together.

\section{ANALYSIS OF THE CURRENT SITUATION OF DIVERSIFIED LEARNING SPACE USE}

\subsection{Data Collection}

Network questionnaire is the main method to collect data in this study, including: writing outline, publishing and collecting questionnaire.

In this study, the questionnaire for users was compiled and revised on the basis of the observation and analysis of different types of learning space and the current situation of the use of space, and the correlation analysis of the existing diversified learning space. The outline of the questionnaire mainly involves the following parts.

(1) Personal information of the interviewee. The main purpose of this question is to know the grade and major information of the interviewees.

(2) Ask questions about the learning spaces that the interviewees like or often visit. The purpose is to find out what kind of learning environment the respondents like and under what circumstances they will use different types of learning space.

(3) Ask questions about the learning space currently used by the interviewees. The purpose is to find out what deficiencies the respondents think the current learning space needs to be improved.

A total of 120 questionnaires were distributed in this study, and 105 valid questionnaires were collected. The effective questionnaire recovery rate was $87.5 \%$.

\subsection{Data Analysis}

This study mainly investigates the users of different types of learning space, so as to study the user satisfaction of different types of learning space. Therefore, in the selection of the survey objects, strict sampling was not carried out according to the demographic variables such as the major and grade of the survey objects.

\subsubsection{Learning Space Preference Analysis}

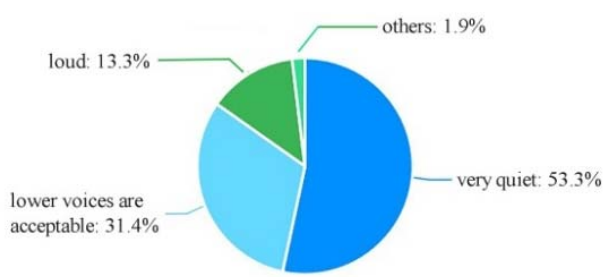

very quiet lower voices are acceptable loud others Figure 1 Types of learning environment that college students like 
Table 1. Statistical table of college students' expectation of learning space

\begin{tabular}{|l|l|}
\hline What college students hope to improve & Number of questionnaires \\
\hline No problem & 15 \\
\hline Install the air conditioner & 40 \\
\hline Occupy a seat & 6 , Among them, there are 5 self-study rooms and 1 library \\
\hline Fewer seats, fewer power outlets & 7 \\
\hline Comfort & 9 , There are four seats \\
\hline More private space & 7 \\
\hline $\begin{array}{l}\text { Want to learn, can't find empty classroom, don't know which is } \\
\text { occupied }\end{array}$ & 5 \\
\hline Quiet environment & 10 , One of them is too quiet \\
\hline Provide a place to recite & 2 \\
\hline Provide a safe place to collect mobile phones & 2 \\
\hline Provide special learning places with computers & 1 \\
\hline More study rooms close to dormitory & 1 \\
\hline Humanized service facilities & 2 \\
\hline Hygienic environment of learning space & 4 \\
\hline
\end{tabular}

According to the survey results, the vast majority of students prefer to study in a quiet environment, accounting for $84.7 \%$, and most of them prefer a very quiet learning environment, accounting for 53.3\%. Under this condition, college students are more inclined to quiet learning space. For example, in formal learning space, classrooms and libraries account for $70.5 \%$ and $72.4 \%$ of all students respectively, while in informal learning space, self-study rooms account for $77.1 \%$.

\subsubsection{Satisfaction Analysis of Learning Space}

From dissatisfied, general, relatively satisfied to satisfied and very satisfied, 1-5 points were recorded respectively, so 3 points were taken as the observation value of medium intensity. Through data analysis, from the perspective of perceived results, the average satisfaction is 3.57. Students are more satisfied with the use of diversified learning space, but the degree of satisfaction is not too high.

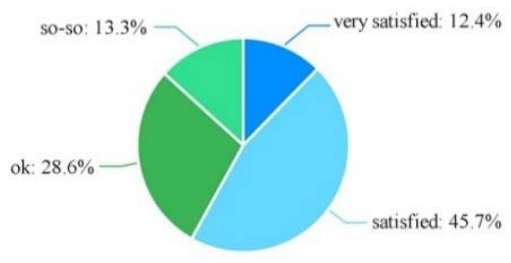

very satisfied satisfied ok so-so unsatisfied Figure 2 The survey results of satisfaction with the use of diversified learning space

\subsubsection{Analysis of Factors Influencing the Satis- faction of College Students' Learning Space Use}

A total of 105 questionnaires were collected, and the statistics of what college students think should be improved are shown in Table 1.
The above results are generalized and classified. The lack of empty classroom can be summarized as opaque learning space information. Installation of air conditioning, comfort, quiet environment and sanitary environment of learning space can be summarized as the environmental comfort of learning space. Seat occupation, less seats and less power outlets can be summarized as the management of learning space. Humanized service facilities and safe collection of mobile phones can be summarized as humanized service. Providing easy to recite places, providing special places with computers for learning, and more self-study rooms close to dormitories can be summarized as the function diversification of learning space. More private space can be summed up as personal space. The statistical results are as follows (Table 2).

It can be concluded that the most important factor affecting college students' satisfaction with the use of diversified learning space is the comfort of learning space environment. Among them, the appeal for the installation of air conditioning accounted for more than half of the total. It can be seen that students generally hope to end the situation of too hot summer and insufficient heating in winter.

\subsubsection{Analysis on the Use of E-learning Space}

There is a great difference in the form between online learning space and formal or informal learning space. Through online learning, time and space are no longer the factors limiting learning activity. Even thousands of miles away can also be in the same "classroom", you can watch the course playback at any time to fill the gaps, which provides great convenience for learning. But through the network space to learn, teachers and students cannot communicate face to face; there are also greater limitations in the test. Students can only learn autonomously through the learning materials uploaded by the teacher and the recording \& 
broadcasting class and the teacher cannot grasp the students' class status and performance in the first time. Lack of effective participation and guidance of teachers, for students with poor self-control, learning effect cannot be guaranteed.

Table 2. Summary statistics of college students' expectation of learning space

\begin{tabular}{|l|l|}
\hline Expectations & Data \\
\hline $\begin{array}{l}\text { The information of learning space is } \\
\text { not transparent }\end{array}$ & 5 \\
\hline Comfort of learning space environment & 64 \\
\hline Management of learning space & 13 \\
\hline Humanized service & 4 \\
\hline Diversified functions of learning space & 3 \\
\hline Personal space & 7 \\
\hline
\end{tabular}

Generally speaking, the popularity of online learning space in a short period of time has brought a lot of convenience for students and teachers who cannot go back to school, but also inevitably has many disadvantages.

\section{COUNTERMEASURES AND SUGGESTIONS}

\subsection{Make Full Use of the Internet Plus Big Data Environment to Create Network Learning Space}

\subsubsection{Making Use of Cyberspace to Facilitate Distance Learning}

With the advent of the information age and the establishment of a learning society, great changes will take place in the future learning space. The change of learning style will inevitably lead to the change of learning space. The design of learning space suitable for future learning style will help to promote the development of education and improve the quality of learning. In order to improve the quality of personnel training and teach students in accordance with their aptitude, internet plus big data and virtual reality technology are applied to personalized learning and create network learning space represent the general trend.

According to the data, more than 100 million students are using online education. From the State to the local, and then to various educational institutions have launched their own characteristics of online education classroom. Including preschool education, $12 \mathrm{~K}$, vocational college, undergraduate and so on, providing different teaching resources to meet the diverse needs of different groups [4].

\subsubsection{Improving the Service Function of the Platform and Providing High-quality Learning Resources}

First of all, network learning space is based on network learning environment, which requires users to have a certain degree of computer use level, and the cumbersome setting of some platforms reduces learners' enthusiasm for network learning. This requires distance education developers to optimize the platform settings to make the operation page concise and easy to use. Second, the online course platform needs to improve its service function and provide high-quality learning resources. This is conducive to improving learning initiative, making learners happy to use the network learning platform for autonomous learning, and realizing the significance of distance teaching to the greatest extent (Table 3).

Table 3. Frequency of learners using learning platform in open and distance education

\begin{tabular}{|l|l|l|l|l|l|}
\hline Content & \multicolumn{5}{|c|}{ Different answers } \\
\hline Frequency of use & never & occasionally & very seldom & often & frequently \\
\hline Percentage (\%) & 6.8 & 43.20 & 15.65 & 29.25 & 5.1 \\
\hline
\end{tabular}

\subsubsection{Combining the Advantages of Traditional Teaching to Improve the Effectiveness of Learning}

Due to the long-distance nature of online learning space, teachers and students cannot communicate face to face, and some traditional teaching methods are difficult to achieve, which affects the quality of online teaching to a certain extent. Teachers and students are expected to improve the effectiveness of teacher-student interaction through online survey. However, many network platforms still have unreasonable setting of teacher-student discussion area, poor operability, and even no teacher-student discussion area. Learners cannot solve their own problems in the first time. And some learners hope that the platform can also provide online homework, online examination functions, through the homework and examination to detect their learning status. Therefore, distance education designers should combine the advantages of traditional teaching to optimize the network learning space, so as to improve the students' satisfaction with the network learning space.

\subsection{Investigate and Understand Students' Needs and Carry out Humanized Design}

Learner-centered, technology-enhanced, diversity, flexibility and sustainability are the development 
direction of learning space design and practice in colleges and universities in the future. The famous architect Herman Hertzberger once said, "architects must also observe what people are doing, but sadly, most architects are only interested in the building itself, not the users of the building." In the construction of learning space, designers and constructors often implement it according to the opinions of superior leaders and relevant parties, and do not really consider the needs of service objects [5]. Students should not only be the users of learning space, but also the design participants of learning space. By combining with students' suggestions, we can better improve the effectiveness of learning space, so as to improve students' satisfaction with the use of learning space.

\subsection{Fully Develop Learning Space and Create a Good Learning Atmosphere}

The improvement of learning space can not only fully develop the potential space and solve the problem of students' learning difficulty, but also the learning behavior in these learning spaces is no longer limited to individual activities, more is the communication and interactive learning between students. These potential learning spaces provide necessary conditions for students to "communicate" and "cooperate" and break the boundaries of each functional space. On the basis of the existing school resources, it is necessary to fully develop and utilize the existing space resources to make up for the lack of single function of traditional learning space, and to create a mixed and diversified non positive learning space for students to accommodate a variety of learning behaviors such as independent learning, group learning and collective activities.

Relevant research results show that diversified learning space has a significant positive effect on undergraduates' professional knowledge, cutting-edge achievements, practical ability, expression ability, information literacy, critical thinking, problem solving and future planning ability [6]. Therefore, to establish and improve the learning space system in colleges and universities, pay attention to the role of different dimensions of learning space, and provide differentiated environmental support for the ability development of students with different backgrounds, have become the problems that educators should consider seriously.

\section{CONCLUSION}

The factory style and passive teaching space paradigm based on teaching needs to be adjusted to a new learning space paradigm to encourage innovation as soon as possible. At the same time, with the advent of the information age and the establishment of a learning society, the learning space will change significantly. Learner centered, technology enhanced, diverse and flexible space, and sustainability are the development direction of learning commons design and practice in colleges and universities in the future. The change of learning style will inevitably lead to the change of learning space. The design of learning space suitable for the future learning style will help to improve the learning effect and students' satisfaction with the use of learning space.

\section{AUTHORS' CONTRIBUTIONS}

Writing: Hongbo Shi, Zhuomei Zhou. Providing case and data: Bohan Gao, Yu Xiao, Rong Zhu, and Yuqing Zhu. Providing revising advice: Bohan Gao, Hongbo Shi.

\section{ACKNOWLEDGMENTS}

Sponsored by Ministry of Education humanities and social sciences research project special task (18JDGC014), Shandong colleges' research project of teaching reform (M2018B336), and Harbin Institute of Technology (JGYJ-2019037, HIT.HSS.HXJS202006).

\section{REFERENCES}

[1] Wang Fanghua. "Internet plus" and business school education. Shanghai Management Science, 2015, 37 (3): 2-5.

[2] Yan Jianzhang, Sun Shanshan. On the creation of university informal learning space. Higher Education Research, 2019, 40 (1): 81-85.

[3] Qi Yujuan, He Xiangyang. An empirical study on the discussion process of college students in elearning space. China Medical Education Technology, 2019, (2): 131-137.

[4] Deng Zhijian. Problems and countermeasures in the construction of learning platform for open and distance education: from the perspective of learners. Education and Teaching Forum, 2020 (13): 353354.

[5] Liu Yajie. Investigation and research on the use of informal learning space in universities: taking the old campus of S University as an example. Sichuan Normal University, 2019.

[6] Bao Zhimei. The current situation of learning environment in colleges and universities and its influence on the development of undergraduates' ability. Jiangsu Higher Education, 2020 (3): 15-22. 